\title{
Time domain reflectometry for measuring soil water content in range surveys
}

\author{
TIM L. REEVES AND MICHAEL A. SMITH
}

\begin{abstract}
Authors are research associate, and associate professor, Range Management Department, University of Wyoming, Laramie 82071.
\end{abstract}

\begin{abstract}
Time Domain Reflectometry (TDR) is introduced as a viable alternative for measuring soil water content for rangeland surveys. The method is based on a strong relationship between the complex dielectric constant of soil and volumetric soil water. Volumetric water content $\left(\theta_{\mathrm{v}}\right)$, measured by TDR and gravimetrically, was compared for 2 rangeland sites. TDR underestimated $\theta_{\mathrm{v}}$ when compared to gravimetric samples for all data. Potential causes of this error and possible solutions are discussed. Some advantages and disadvantages of the method are discussed.
\end{abstract}

Key Words: TDR, time domain reflectometry, soil moisture, volumetric water content, survey

Standard methods commonly used for measuring soil water content, such as neutron moderation, tensiometers, gypsum blocks, or gravimetric samples have several disadvantages in the precise, accurate, or timely collection of data in the field. Time Domain Reflectometry (TDR) is a relatively new soil water measuring technqiue (Hoekstra and Delaney 1974, Davis and Annan 1977, Topp et al. 1980, Topp and Davis 1985a). TDR is accurate, requires no calibration between soil types or bulk densities, is not affected by salt content, and the sampling equipment is mobile and easy to use. The purpose of this paper is to briefly introduce and describe TDR, compare TDR measured water contents to gravimetric samples, and evaluate its use under field conditions.

Time Domain Reflectometry is a technology in which an electromagnetic pulse is propagated down a transmission line and the reflection of the pulse is analyzed with an oscilloscope to estimate the complex dielectric constant $\left(\epsilon^{*}\right)$ of a medium. The complex dielectric constant is an electrical property that represents the ratio of the dielectric permittivity of the media being measured to the dielectric permittivity of free space (Hoekstra and Delaney 1974). Using TDR, the complex dielectric constant $\left(\epsilon^{*}\right)$ of soil media can be estimated (Topp et al. 1980). When measured in the $\mathrm{MHz}$ to $\mathrm{GHz}$ frequency range, the $\epsilon^{*}$ of a soil is strongly dependent on the volumetric water content $\left(\theta_{\mathrm{v}}\right)$. Topp et al. (1980) evaluated this technique in several soils and other porous media and determined $\epsilon^{*}$ to be independent of bulk density, soil type, particle size distribution, and salt content. They presented the following calibration curve for use in mineral soils:

$$
\theta_{\mathrm{v}}=-5.30 \times 10^{-2}+2.92 \times 10^{-2} \epsilon^{*}-5.5 \times 10^{-4} \epsilon^{* 2}+4.3 \times 10^{-6} \epsilon^{* 3}
$$

In applying 95\% confidence bands to Equation 1, Topp et al. (1980) reported this relationship to be very accurate across all soils and water contents studied when compared to gravimetric determinations $\left( \pm 0.013\right.$ in $\left.\theta_{\mathrm{v}}\right)$.

In practice, instruments or TDR probes are constructed that allow the measurements of $\epsilon^{*}$ in soils using a Time Domain Reflectometer, an electronic device primarily designed to detect and

Contribution from the University of Wyoming Agr. Exp. Sta. Pub. JA1638.

Manuscript accepted 31 August 1991. locate faults in transmission lines. Topp et al. (1984), Reeves et al. (1989), Zegelin et al. (1989) and others have described different styles of TDR instrumentation developed for measuring $\theta_{\mathrm{v}}$ in soils. Figure 1 shows a TDR probe which was built at the University of

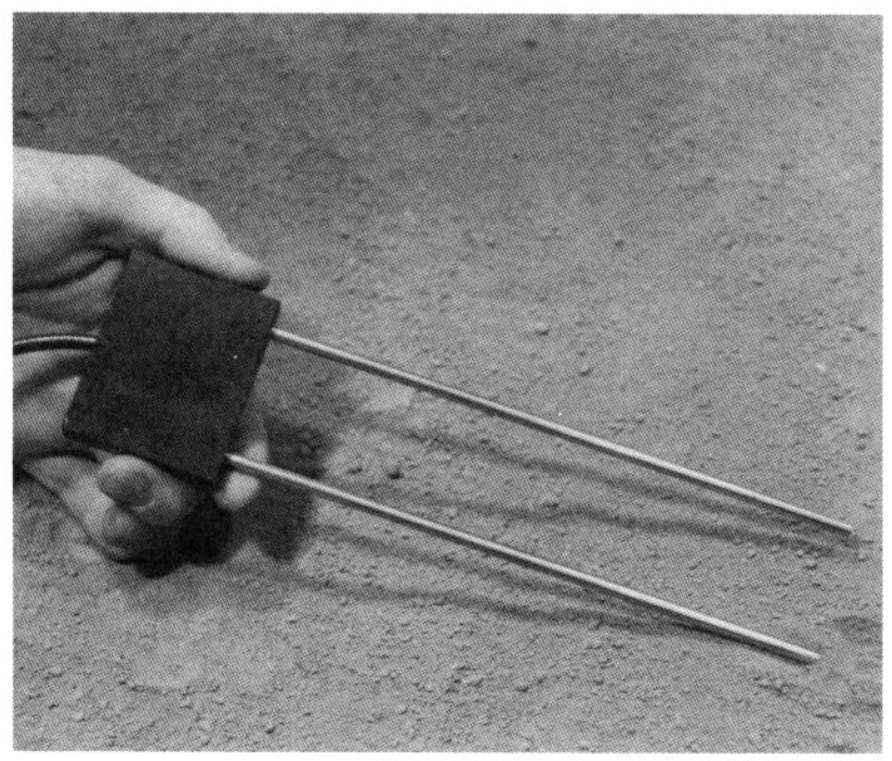

Fig. 1. TDR probe with $20-\mathrm{cm}(4.8 \mathrm{~mm}$ diam. $)$ stainless steel rods spaced at $4 \mathrm{~cm}$ (on center) for wave guides.

Wyoming. The parallel rods or wave guides of the probe act as a balanced transmission line. When they are inserted into the soil, the soil around and between the wave guides also becomes part of the transmission line. This response area has been discussed by Baker and Lascano (1989). They indicated that the area of influence perpendicular to the wave guides was extremely narrow ( 30 $\mathrm{mm}$ ). Because of this property, wave guides can be inserted horizontally into a soil and $\theta_{\mathrm{v}}$ measurements taken with high degrees of vertical resolution or very close to the soil surface. The complex dielectric constant of the soil is determined by interpreting the reflected signal on the oscilloscope of the Time Domain Reflectometer (Topp et al. 1982, Stein and Kane 1983). The reflected signal on the oscilloscope can be interpreted by the user in the field or digitized for later, more precise, interpretation.

\section{Methods}

Two sites were used to compare $\theta_{\mathrm{v}}$ measured by TDR and by gravimetric methods. Site 1 was to be burned for control of mountain big sagebrush (Artemisia tridentata Nutt. spp. vaseyana (Rybd.) Boivin). The soils were deep to shallow loams with coarse limestone aggregates and were classified as fine-loamy, mixed Typic Cryoborolls. The dominant vegetation was mountain big sagebrush, Idaho fescue (Festuca idahoensis Elmer), and western 
wheatgrass (Pascopyrum smithii (Rybd.) A. Love). Normal precipitation was $500 \mathrm{~mm}$ per annum. Site 2 was in the northern mixed prairie in western Nebraska. The soils were deep sandy loams and were classified as coarse silty, mixed (calcareous) mesic, Ustic Torriothents. The dominant vegetation was needleandthread (Stipa comata Trin. \& Rupr.) and threadleaf sedge (Carex filifolia Nutt.). Normal precipitation was $350 \mathrm{~mm}$ per annum.

At site 1, 24 surface soil moisture measurements were taken at approximate $20-\mathrm{m}$ increments along a $500-\mathrm{m}$ transect. Thirty-six (36) soil moisture measurements were collected from permanent sampling points at site 2 . Gravimetric samples of a known volume were taken at both sites by inserting a $20-\mathrm{mm}$ diameter coring tube to a $15-\mathrm{cm}$ depth. Because the tube was inserted to an exact depth, potential changes to the core volume caused by compaction in the sampling tube could be ignored. Gravimetric samples were transferred to the laboratory, weighed, and dried at $104^{\circ} \mathrm{C}$ until an equilibrium weight was achieved. The core volume was used to convert water contents from a dry weight basis to a volumetric basis for comparison with the TDR values.

A TDR probe (Fig. 1) and a Tektronix model 1502 TDR Cable Tester (Tektronix, Inc., Beaverton, OR) ${ }^{1}$ were used to perform soil moisture measurements. The probe with $20-\mathrm{cm}$ wave guides was connected to the TDR cable tester using $50 \mathrm{ohm}$ coaxial cable. Figure 2 shows the application of TDR in the field. The $20-\mathrm{cm}$

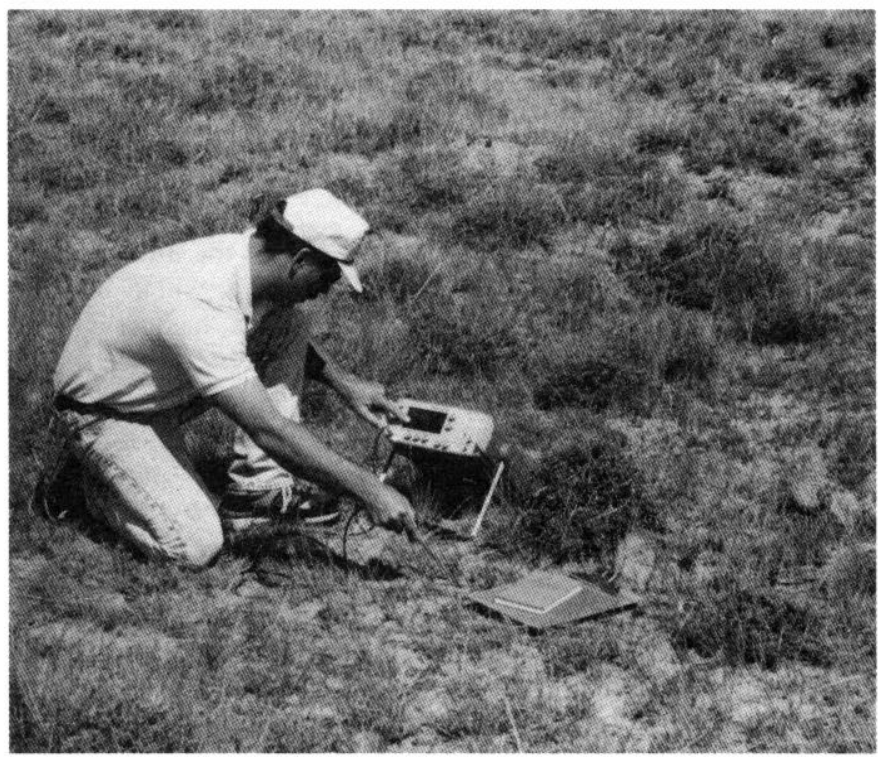

Fig. 2. TDR applied during a field survey. The signal from the TDR probe is reflected back to the Time Domain Reflectometer and interpreted to determine $\epsilon^{*}$. $\theta_{\mathrm{v}}$ is calculated using Equation 1.

TDR probe was inserted into the soil at an approximate $48^{\circ}$ angle so that $\theta_{\mathrm{v}}$ was measured between 0 and $15 \mathrm{~cm}$ of soil depth. Reflected TDR signals were interpreted in the field and Equation 1 was used to calculate volumetric water content. Measurement differences or errors were calculated by substracting $\theta_{\mathrm{v}}$ measured by TDR from $\theta_{\mathrm{v}}$ measured gravimetrically. The standard deviation associated with the mean error was also calculated.

\section{Results and Discussion}

The difference in $\theta_{\mathrm{v}}$ between replicate samples was small at both survey sites. This was especially true for site 2 , where the difference between the high and low value in $\theta_{\mathrm{v}}$ for gravimetric samples was only $.028(2.8 \%)$. Site 1 , however, did have relatively higher

'Mention of vendor is only for convenience and does not imply an endorsement by the authors or the University of Wyoming. observed water contents than site 2 , and this provided 2 ranges of $\theta_{\mathrm{v}}$ which were evaluated.

Sampling by TDR was extremely time efficient; a measurement could be taken and $\theta_{\mathrm{v}}$ calculated in less than 1 minute. In all cases, TDR underestimated the water content measured gravimetrically (Fig. 3). The mean error in $\theta_{\mathrm{v}}$ at site 1 was $-.105(-10.5 \%)$ and the mean error in $\theta_{\mathrm{v}}$ at site 2 was $-0.032(-3.2 \%)$. The error associated with the TDR measurement appears to be systematic for both sites.

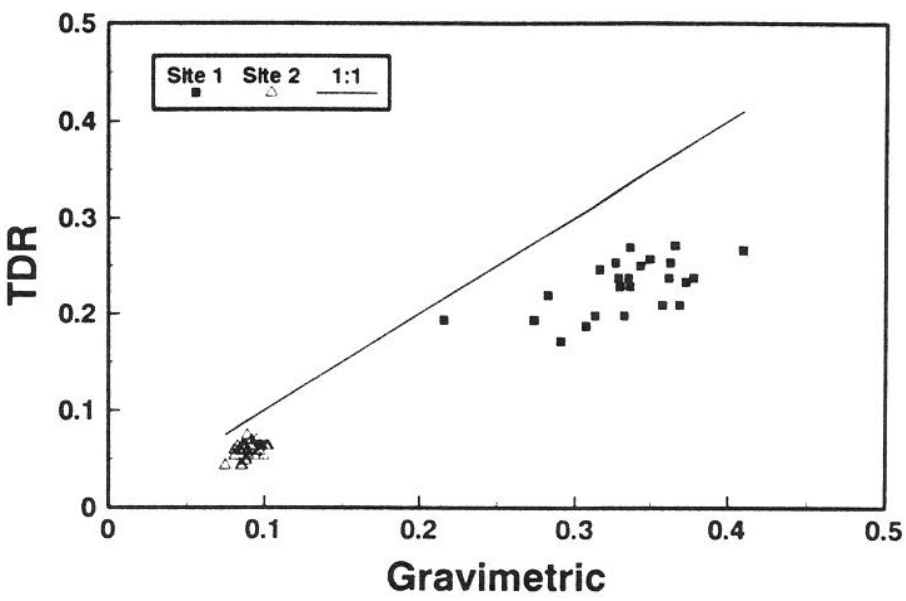

Fig. 3. Comparison of $\theta_{\mathrm{v}}$ measured by TDR and by gravimetric sample. The line denotes a perfect $1: 1$ relationship.

Concurrently, the sampling error was extremely small $(\mathrm{s}=0.031$ and $\mathrm{s}=0.008$ for site 1 and site 2 , respectively). We believe that a systematic measurement error was introduced when the probe was inserted into the soil. The coarse limestone aggregates associated with the soils at site 1 caused considerable difficulty in inserting the TDR probe by hand. Less difficulty was noted in site 2 and better accuracy was achieved at this site than at site 1 (Fig. 3). Baker and Lascano (1989) stated that any "wobble" caused by inserting the rods would introduce air gaps and cause "systematic underestimates" in water content. Topp and Davis (1985a) suggested that this error could be minimized by inserting the probes at an angle. Although our measurements were taken by inserting the probe at an angle, these data suggest that measurement accuracy is very sensitive to the air gap effect. It is also possible at site 1 that the TDR wave guides encountered limestone fragments when inserted into the soil that were not in the gravimetric core. This effect would also lower the $\theta_{\mathrm{v}}$ measured by TDR and increase the error with respect to the gravimetric measurement.

\section{Conclusions}

These data showed systematic underestimates in $\theta_{\mathrm{v}}$ measured by TDR compared to $\theta_{\mathrm{v}}$ measured gravimetrically. The underestimation was more prominent in the soil which contained large coarse limestone aggregates and caution should be used when applying the TDR technique in coarse soils. These data suggest that air gaps, created when the TDR probe was inserted into the soil, was the primary cause of the error. The air gap effect could be minimized by the use of smaller diameter rods, tapered rods, or a designed insertion guide or template. Smaller, tapered rods would be easier to insert into a soil and an insertion guide would decrease any wobble. On sites where repeated measurements for $\theta_{\mathrm{v}}$ are desired, permanent probe installations could be made or probes could be buried (Reeves et al. 1989, Topp and Davis 1985b). Air gaps around permanent probe installations would diminish over time. Depending on the objectives of the user, the specific characteristics of the probe used, and the desired degree of accuracy, double sampling could be applied to correct systematic errors. 
TDR can be applied in the field as a viable alternative for measuring soil water content. Measurements of $\theta_{\mathbf{v}}$ can be made from dry to nearly saturated conditions. The method is easily applied and very little training is involved. The major advantage of this technique is that volumetric soil water can be quickly measured without calibrating for specific soils. Volumetric soil water is a more appropriate term for most hydrological and plant physiological concerns, but its calculation previously required a knowledge of both the bulk density and the water content by depth. Because of a very narrow response area perpendicular to the wave guides $\theta_{v}$ measurements can be taken with high degrees of vertical resolution or very close to the soil surface. The initial cost of the time domain reflectometer is relatively high, being slightly more expensive than a neutron probe. It does not, however, present a radiation hazard or require licensing. The method can be automated and the readings between different probes can be multiplexed (Baker and Allmaras 1990, Heimovaara and Bouten 1990).

\section{Literature Cited}

Baker, J.M., and R.J. Lascano. 1989. The spatial sensitivity of timedomain reflectometry. Soil Sci. 147:378-383.

Baker, J.M., and R.R. Allmaras. 1990. System for automating and multiplexing soil moisture measurement by time-domain reflectometry. Soil Sci. Soc. Amer. J. 54:1-6.

Davis, J.L., and A.P. Annan. 1977. Electromagnetic detection of soil moisture: progress report 1. Can. J. Remote Sensing 3:76-86.
Heimovaara, T.J., and W. Bouten. 1990. A computer-controlled 36channel time domain reflectometry system for monitoring soil water contents. Water Resour. Res. 26:2311-2316.

Hoekstra P., and A. Delaney. 1974. Dielectric properties of soils at UHF and microwave frequencies. J. Geophys. Res. 79:1699-1708.

Topp, G.C., and J.L. Davis. 1985a. Time-domain reflectometry (TDR) and its application to irrigation scheduling, p. 107-127 In: D. Hillel, ed. Advances in Irrigation Scheduling, vol. 3. Academic, Orlando, Fla.

Topp, G.C., and J.L. Davis. 1985b. Measurement of soil water content using time-domain reflectometry (TDR): a field evaluation. Soil Sci. Soc. Amer. J. 49:19-24.

Topp, G.C., J.L. Davis, and A.P. Annan. 1982. Electromagnetic determination of soil water content using TDR: $I$. Applications to wetting fronts and Steep Gradients. Soil Sci. Soc. Amer. J. 46:672-678.

Topp, G.C., J.L. Davis, and A.P. Annan. 1980. Electromagnetic determination of soil water content: Measurement in coaxial transmission lines. Water Resour. Res. 16:574-582.

Topp, G.C., J.L. Davis, W.G. Baily, and W.D. Zebchuk. 1984. The measurement of soil water content using a portable TDR handprobe. Can. J. Soil Sci. 64:313-321.

Reeves, T.L., S.M. Elgezawi, and T.G. Kaser. 1989. The use of time domain reflectometry for monitoring in situ volumetric water content in processed oil shale, p. 218-225. In: J.H. Gary, ed. 22nd Oil Shale Symp. Proc. Colorado School of Mines Press, Golden, Colo.

Stein, J., and D.L. Kane. 1983. Monitoring the unfrozen water content of soil and snow using time domain reflectometry. Water Resour. Res. 19:1573-1584.

Zegelin, S.J., I. White, and D.R. Jenkins. 1989. Improved field probes for soil water content and electrical conductivity measurement using time domain reflectometry. Water Resour. Res. 25:2367-2376. 